\title{
Retraction of cutaneous specimens: tumours and margins after surgical excision
}

Marine Sevray ${ }^{1 *}$, Emilie Brenaut ${ }^{1,2^{*}}$, Yann Grangier $^{3}$, Laurent Misery ${ }^{1,2}$, Florence Poizeau ${ }^{4}$, Frédéric Staroz ${ }^{5}$

1. Dermatologie, CHU Brest, Brest, France

2. Faculté de Médecine et des Sciences de la Santé de Brest, Université de Bretagne Occidentale, Brest, France

3. Chirurgie esthétique et médecine esthétique, Clinique de l'Océan, Quimper, France

4. REPERES, Recherche en Pharmaco-épidémiologie et recours aux soins, UPRES EA 7449, Université de Rennes, Rennes, France

5. Anatomo-cyto-pathologie, Ouest Pathologie, Quimper, France

*These authors contributed equally to this work

Corresponding author: Marine Sevray, Department of Dermatology, University Hospital, 2 avenue Foch 29200 Brest, France (tel: +33 2982233 15; fax: +33 2982233 82; e-mail: marine.sevray@hotmail.fr)

This article has no funding source.

The authors have no conflict of interest to declare.

Abstract: 242 (words count)

Text: 2229 (words count)

References: $15 \quad$ Figure: $2 \quad$ Tables: 4

Keywords: skin retraction, shrinkage, cutaneous specimens, skin carcinoma, melanoma, margins 


\section{Abstract}

Aims: In previous studies, skin retraction of dermato-pathological specimens after the surgical excision of tumours was calculated at $30 \%$ for the surface, with approximately $20 \%$ for the length and $15 \%$ for the width. The aim of this study was to analyse the retraction of the specimens and the retraction of the lesion and the margins.

Methods: Patients who underwent excision of a skin tumour between January 2013 and July 2014 were randomly included.

Results: A total of 104 patients was included. There were 52\% male with a mean age of 68.3 years. Seventy-eight percent of the lesions were malignant ( $51 \%$ were basal cell carcinoma, $10 \%$ squamous cell carcinoma). The retraction of the area of the specimen (29\%) was significantly greater than the retraction of the tumour (21\%). On multivariate analysis, the localization and the duration of fixation were independent predictors of the specimen area retraction. The retraction of the specimen was $17 \%$ in length and $15 \%$ in width. The retraction of the margins was calculated at $19 \%$ in length and $12 \%$ in width. The surgeon correctly evaluated the localization of the smallest margin in $55 \%$ of cases.

Conclusions: Our study provided additional data regarding the retraction of the tumours and margins. The guidelines for surgical excision of skin cancers recommend a clinical margin before excision, but the evaluation of the sufficiency of the margins is based on histological measurement. Our data are useful for the interpretation of the sufficiency of the margins. 


\section{$\underline{\text { Text }}$}

\section{INTRODUCTION}

After surgical excision of skin tumours, the retraction of the specimen's area has been calculated at approximately $30 \%$ from the moment before excision to 5 minutes after excision [1]. Formalin fixation added only a small amount of retraction, and the majority of tissue shrinkage occurred immediately after excision $[2,3]$. The power of the retraction varied significantly according to the region of the body [1]. Retraction has been calculated at approximately $20 \%$ for the length and $15 \%$ for the width of the specimen [2-4]. No study evaluated the retraction of the lesion, the specimen and the margin separately for all skin tumours type. These data would be useful for interpreting the margins of the histopathological result. The guidelines for the surgical excision of skin cancer (skin carcinoma and melanoma) recommend a clinical margin before excision, but there are no recommendations for the histological margins. Nevertheless, the evaluation of the sufficiency of the margins is based on this histological measurement. There are discrepancies between surgical and histopathological measurement; therefore, dermatologists and surgeons often discuss whether another larger excision is necessary in multidisciplinary meetings. The aim of this study was to analyse the retraction of the lesions, the specimens and the margins of cutaneous specimens. 


\section{METHODS}

In this observational, prospective and monocentric study, patients who had a skin excision by the surgeon in the study (YG) between January 2013 and July 2014 were randomly included. Measurements were taken at three different times:

1) Before excision, the surgeon collected the following data: localization of the lesion, specimen length and width in millimetres, lesion length and width in millimetres and the smallest margin in millimetres designed on a schematic diagram, with the orientation of the specimen (Figure 1).

2) After formalin fixation, the pathologist collected the same information (length and width of the specimen and the lesion, smallest margin in millimetres) and the duration of formalin fixation.

3) After fixation, cutting and staining, the specimen slide was analysed with a microscope by one of the four pathologists who participated in the study. Information collected included the diagnosis of the tumour and the localization of the smallest histological margin with its measurement in millimetres. All measurements, except the microscopic, were performed with a standard millimeter ruler. As the surgeon did elliptical excision, we noted whether the localization of the smallest margin was the same as the smallest margin indicated by the surgeon. The percentage of retraction was calculated for the various measurements.

We calculated the areas of the specimen and lesion before excision (S1) and after formalin fixation (S2) with the formula of the area of an ellipse: $S=$ length $x$ width $x \pi / 4$, and the percentage of the retraction before excision and after formalin fixation was calculated with the formula $R=1-(S 2 / S 1)$.

We calculated margin length and width with the formula: (diameter of specimen - diameter of lesion)/2 to obtain additional data regarding margins in addition to the smallest margin measured.

Our primary objective was to analyse the percentage of retraction of the lesion, specimen and margins of cutaneous specimens before excision and after formalin fixation. The other objectives were to analyse the percentage of retraction according to gender, age, localization, area before excision, duration of fixation and the type of lesion. We also analysed the percentage of concordance between the surgeon-estimated margin and the pathologist's confirmed smallest margins, and when the margins were concordant, we calculated the percentage of retraction of the smallest margin.

\section{Statistical analysis}

Our data were analysed with descriptive and analytic methods. The quantitative variables were described using means and standard deviations. The qualitative variables were described using frequencies and percentages. The retraction of the specimens and the lesions were compared with paired t-tests. Linear regression was performed to study the association between the retraction as the dependent variable and a set of characteristics as the explanatory variables (gender, age as a 
continuous variable, localization, specimen or lesion area before excision, duration of fixation as a continuous variable and type of lesion). Univariate linear regressions and adjusted linear regressions were performed to eliminate potential confounders. For all statistical analyses, type 1 error was set at 5\%. All data were analysed using RStudio Version 1.0.136 (RStudio, Inc, Boston, MA, USA). 


\section{RESULTS}

One hundred and four patients were included. The population was composed of $52 \%$ of men, with a mean age of $68.3 \pm 17.5$ years (range 12-92). The characteristics of the lesions are described in Table 1.

Table 1: Characteristics of the 104 lesions studied.

\begin{tabular}{|c|c|c|}
\hline \multirow{3}{*}{ Diagnosis, $\mathrm{n}(\%)$} & & $\mathrm{n}=104$ \\
\hline & $\begin{array}{l}\text { Malignant } \\
\text { Basal cell carcinoma } \\
-\quad \text { Nodular } \\
-\quad \text { Infiltrative or morpheaform } \\
\text { - } \quad \text { Superficial } \\
\text { Squamous cell carcinoma } \\
-\quad \text { Microinvasive } \\
-\quad \text { Invasive } \\
\text { - Poorly differentiated } \\
\text { Melanoma } \\
\text { Bowen's disease } \\
\text { Pre-epitheliomatous keratosis } \\
\text { Trichoblastoma } \\
\text { Composite tumour }\end{array}$ & $\begin{array}{l}82(79) \\
37(36) \\
15(14) \\
1(1) \\
1(1) \\
9(9) \\
1(1) \\
8(8) \\
5(5) \\
3(3) \\
1(1) \\
1(1)\end{array}$ \\
\hline & $\begin{array}{l}\text { Benign } \\
\text { Nevi } \\
-\quad \text { Dermal } \\
-\quad \text { Compound } \\
-\quad \text { Junctional } \\
\text { Seborrheic keratosis } \\
\text { Histiocytofibroma } \\
\text { Clear cell acanthoma } \\
\text { Scar } \\
\text { Dilated pore of Winer } \\
\text { Glomus tumour } \\
\text { Post inflammatory pigmentation }\end{array}$ & $\begin{array}{l}22(19) \\
3(3) \\
5(5) \\
4(4) \\
3(3) \\
2(2) \\
1(1) \\
1(1) \\
1(1) \\
1(1) \\
1(1)\end{array}$ \\
\hline Localization, $\mathrm{n}(\%)$ & $\begin{array}{l}\text { Head/neck } \\
\text { Trunk } \\
\text { Inferior limb } \\
\text { Superior limb }\end{array}$ & $\begin{array}{c}59(57) \\
26(25) \\
11(11) \\
8(8)\end{array}$ \\
\hline $\begin{array}{l}\text { Duration of formalin } \\
\text { fixation, } n(\%)\end{array}$ & $\begin{array}{l}24 \text { hours } \\
48 \text { hours } \\
72 \text { hours } \\
96 \text { and } 120 \text { hours }\end{array}$ & $\begin{array}{l}39(38) \\
27(26) \\
17(16) \\
21(20)\end{array}$ \\
\hline
\end{tabular}


Among the 11 squamous cell carcinoma (SCC), 9 (82\%) were located in the head and neck, and $2(18 \%)$ were located in the limbs. Basal cell carcinomas $(B C C)(n=53)$ were located in the head and neck in 37 cases $(70 \%)$, in the trunk in 12 cases (23\%) and in the limbs in 4 cases (7\%). Melanoma were located in 3 cases $(37.5 \%)$ in the head and neck, in 3 cases $(37.5 \%)$ in the trunk and in 2 cases $(25 \%)$ in the limbs. The length, width and area before excision and after fixation are presented in Table 2.

Table 2: Mean specimens, lesions sizes and margins before excision and after fixation in macroscopy.

\begin{tabular}{|l|l|c|c|c|}
\hline \multicolumn{2}{|l|}{} & $\begin{array}{c}\text { Before excision } \\
\text { Mean (SD) }\end{array}$ & $\begin{array}{c}\text { After fixation } \\
\text { Mean (SD) }\end{array}$ & $\begin{array}{c}\text { Percentage } \\
\text { of retraction } \\
\text { Mean (SD) }\end{array}$ \\
\hline \multirow{3}{*}{ Specimen } & Length $(\mathrm{mm})$ & $33(13)$ & $27(10)$ & $17(10)$ \\
& Width $(\mathrm{mm})$ & $15(6)$ & $13(5)$ & $15(11)$ \\
& Area $\left(\mathrm{mm}^{2}\right)$ & $441(337)$ & $305(233)$ & $29(13)$ \\
\hline \multirow{3}{*}{ Lesion } & Length $(\mathrm{mm})$ & $11(6)$ & $10(5)$ & $11(16)$ \\
& Width $(\mathrm{mm})$ & $9(4)$ & $8(4)$ & $13(14)$ \\
\hline Smallest margin & Area $\left(\mathrm{mm}^{2}\right)$ & $100(108)$ & $78(87)$ & $21(22)$ \\
\hline Estimated margin* & Size $(\mathrm{mm})$ & $2(1)$ & $2(1)$ & $10(26)$ \\
& Length $(\mathrm{mm})$ & $11(5)$ & $8(4)$ & $19(18)$ \\
& Width $(\mathrm{mm})$ & $3(1)$ & $3(1)$ & $12(58)$ \\
\hline
\end{tabular}

* Estimated margin was calculated with the formula: (diameter of specimen-diameter of lesion)/2 
The percentage of retraction of the specimen and the lesion are presented in Figure 2.

The retraction of the area of the specimen $(29 \%)$ was significantly greater than the retraction of the lesion (21\%), $p<0.001$. Among the 82 malignant lesions, $8(10 \%)$ had a positive margin or a margin smaller than $1 \mathrm{~mm}$.

For the malignant lesions, we analysed the concordance of localization of the smallest margin estimated by the surgeon and confirmed by the pathologist on microscopy. In 45 cases (55\%), it was concordant, in 23 cases (28\%) it was discordant, and information was missing in 14 cases (17\%). In the 45 concordant cases, the mean percentage of retraction of the smallest margin was $1 \%$. Among these 45 concordant cases, the size of the smallest margin was the same for the surgeon and the pathologist in 12 cases (27\%), greater according to the surgeon's measurement in 17 cases $(38 \%)$ and greater according to the pathologist's measurement in 16 cases (36\%). Because of milimeter measurements inaccuracy of the surgeon with a standard millimeter ruler compared the use of a microscope for the pathologist we obtained negative measurements. The sum of positive and negative measurements explained the low mean retraction of $1 \%$.

In malignant lesions, the retraction was analysed according to the diagnosis of the 3 main categories of malignant lesions (Table 3). Bowen's disease, pre-epitheliomatous keratosis, trichoblastoma and composite tumour were not analysed because of their low frequency.

Table 3: Percentage of retraction for main malignant lesions according to the diagnosis.

\begin{tabular}{|l|c|c|c|c|c|}
\hline & $\begin{array}{c}\text { Retraction of area } \\
\text { specimen (\%) } \\
\text { Mean (SD) }\end{array}$ & p-value & $\begin{array}{c}\text { Retraction of area } \\
\text { lesion (\%) } \\
\text { Mean (SD) }\end{array}$ & p-value & $\begin{array}{c}\text { Retraction of } \\
\text { smallest margin (\%) } \\
\text { Mean (SD) }\end{array}$ \\
\hline $\mathrm{BCC}, \mathrm{n}=53$ & $28(14)$ & & $24(21)$ & & $12(28)$ \\
$\mathrm{SCC}, \mathrm{n}=11$ & $24(11)$ & 0.15 & $12(11)$ & 0.08 & $1(13)$ \\
Melanoma, $\mathrm{n}=8$ & $36(9)$ & $10(30)$ & & $31(38)$ \\
\hline
\end{tabular}


The percentages of retraction of the estimated margins calculated for BCC, SCC and melanoma were $17 \%, 15 \%$ and $31 \%$ for length, respectively, and $3 \%, 19 \%$ and $33 \%$ for width, respectively. The differences were not significant.

We analysed the retraction according to gender, age, localization, area before excision, duration of fixation and type of lesion with linear unadjusted and adjusted regression analyses (Table 4).

Table 4: Percentage of retraction according to gender, age, localization, area before excision, duration of fixation and type of lesion.

\begin{tabular}{|c|c|c|c|c|c|c|}
\hline & & $\begin{array}{c}\text { Retraction of } \\
\text { area } \\
\text { specimen } \\
\text { Mean (SD) }\end{array}$ & $\begin{array}{c}\text { p- } \\
\text { values* }\end{array}$ & $\begin{array}{c}\text { Retraction of } \\
\text { area } \\
\text { lesion } \\
\text { Mean (SD) }\end{array}$ & $\begin{array}{c}\text { p- } \\
\text { values* }\end{array}$ & $\begin{array}{c}\text { Retraction } \\
\text { of smallest } \\
\text { Margin } \\
\text { Mean (SD) }\end{array}$ \\
\hline Gender & $\begin{array}{l}\text { Male }(n=54) \\
\text { Female }(n=50)\end{array}$ & $\begin{array}{l}30(15) \\
28(12)\end{array}$ & 0.33 & $\begin{array}{l}21(22) \\
22(22)\end{array}$ & 0.79 & $\begin{array}{l}11(25) \\
9(28)\end{array}$ \\
\hline Age* & $\begin{array}{l}\leq 70 \text { years }(n=49) \\
>70 \text { years }(n=55)\end{array}$ & $\begin{array}{l}31(15) \\
27(12)\end{array}$ & 0.06 & $\begin{array}{l}26(23) \\
17(21) \\
\end{array}$ & 0.57 & $\begin{array}{c}15(22) \\
6(29) \\
\end{array}$ \\
\hline Localization & $\begin{array}{l}\text { Head/neck }(n=59) \\
\text { Trunk }(n=26) \\
\text { Superior } \operatorname{limb}(n=8) \\
\text { Inferior } \operatorname{limb}(n=11)\end{array}$ & $\begin{array}{c}24(12) \\
35(13) \\
43(15) \\
31(7) \\
\end{array}$ & $<0.001$ & $\begin{array}{c}21(22) \\
24(23) \\
30(16) \\
8(21) \\
\end{array}$ & 0.14 & $\begin{array}{l}10(23) \\
19(28) \\
-6(44) \\
2(17) \\
\end{array}$ \\
\hline $\begin{array}{l}\text { Area specimen } \\
\text { before } \\
\text { excision** }\end{array}$ & $\begin{array}{l}<400 \mathrm{~mm}^{2}(\mathrm{n}=62) \\
>400 \mathrm{~mm}^{2}(\mathrm{n}=42)\end{array}$ & $\begin{array}{l}26(13) \\
34(13)\end{array}$ & 0.06 & - & - & - \\
\hline $\begin{array}{l}\text { Area lesion } \\
\text { before } \\
\text { excision** }\end{array}$ & $\begin{array}{l}<100 \mathrm{~mm}^{2}(\mathrm{n}=73) \\
>100 \mathrm{~mm}^{2}(\mathrm{n}=31)\end{array}$ & - & - & $\begin{array}{l}28(13) \\
32(14)\end{array}$ & 0.75 & - \\
\hline $\begin{array}{l}\text { Duration of } \\
\text { fixation** }\end{array}$ & $\begin{array}{l}24 \text { hours }(n=39) \\
48 \text { hours }(n=27) \\
72 \text { hours }(n=17) \\
96 \text { and } 120 \text { hours } \\
(n=21)\end{array}$ & $\begin{array}{l}31(14) \\
28(14) \\
28(11) \\
27(13)\end{array}$ & 0.18 & $\begin{array}{l}22(22) \\
18(21) \\
25(28) \\
21(19)\end{array}$ & 0.84 & $\begin{array}{l}12(29) \\
18(26) \\
0(12) \\
4(28)\end{array}$ \\
\hline Type of lesion & $\begin{array}{l}\text { Benign }(n=22) \\
\text { Malignant }(n=82)\end{array}$ & $\begin{array}{l}32(13) \\
29(14)\end{array}$ & 0.35 & $\begin{array}{l}20(24) \\
22(22) \\
\end{array}$ & 0.81 & $\begin{array}{c}8(18) \\
11(28)\end{array}$ \\
\hline
\end{tabular}

*Univariate linear regression analysis

** Statistical tests used continuous variables

Only the localization of the lesion was associated with the specimen area retraction on unadjusted linear regression analysis. After adjustment for other patient and lesion characteristics, localization ( $p$ $<0.001)$ and duration of fixation $(p=0.04)$ were independently associated with specimen area retraction. No factor was significantly associated with the percentage of retraction of the lesion, neither on univariate nor on multivariate regression analysis. 


\section{DISCUSSION}

In this study, based on 104 cutaneous specimens, the mean retraction of the specimen's area was calculated at $29 \%$. This outcome was consistent with a study by Dumas et al., in which the mean area retraction was evaluated at 31\% five minutes after excision [1]. Previous studies highlighted that the majority of tissue shrinkage occurred immediately after excision and prior to fixation because of intrinsic contractile properties of the tissue itself [2-4]. Formalin fixation added only a small amount of retraction. Retraction in length and width was evaluated at respectively $17 \%$ and $15 \%$ for the specimen and $11 \%$ and $13 \%$ for the lesion. These results were consistent with the results of previous studies; retraction was calculated between $16 \%$ and $21 \%$ for length and between $18 \%$ and $10 \%$ for width [2-4]. Blasdale et al. conducted a study on BCC and reported a mean retraction of the whole specimen widest diameter of $14 \%$, and a significant difference between the $19 \%$ shrinkage of normal skin compared with skin containing tumour tissue which shrank by only $11 \%$ [5] . Concerning factors influencing retraction, the localization was significantly associated with the percentage of retraction. Retraction was greater in the upper extremities than that in the lower extremities, the trunk or the head and neck. In previous studies [1-3], retraction was also greater in the trunk and limbs than that in the head and neck. In our study, gender and age were not independent factors of retraction. In other studies, retraction was less with greater age $[2,6,7]$. Silverman et al. studied 407 malignant melanomas and proposed a formula to determine an in vivo diameter: in vivo diameter $=(1.18$ or 1.25 or 1.33$) \mathrm{x}$ in vitro diameter with 1.18 when age $<50,1.25$ when age 50-59 and 1.33 when age $\geq 60$ [7], however previous studies and ours demonstrated no effect of age on the retraction $[3,5]$. In our study, the longest formalin fixation was associated with a smallest retraction, by contrast with previous studies $[2,3]$.

Our study provides additional data regarding the retraction of tumours and their margins for all skin tumours type. The retraction of the specimen's area was greater than that of the lesion's area. The retraction of the margins was calculated as $19 \%$ for length and $12 \%$ for width. The retraction of the smallest margin is $10 \%$. Of this result we can estimate the smallest margin before excision with the formula: microscopic margin/0,9 $(1-10 \%=0,9)$. The guidelines for the surgical excision of skin cancers (skin carcinoma and melanoma) recommend a clinical margin before excision [8,9]. The margins recommended by the guidelines vary by country, and there is actually no international consensus [8]. There is no recommendation regarding the histological margin, whereas the evaluation of correct margins is based on this histological measurement. There are discrepancies between surgical and histopathological measurements; therefore, dermatologists and surgeons often discuss in multidisciplinary meetings whether another larger excision is necessary. Sufficient removal is essential 
because incomplete removal is considered a poor prognostic indicator, as incomplete removal of lesions is a risk factor for local recurrence. For BCC, incomplete removal of the tumour ranges from $6 \%$ to $25 \%$, depending on the improper intra-operative evaluation of the extent of the tumour [10]. A previous study showed that narrow margins $(1-3 \mathrm{~mm})$ were inadequate for the excision of small, welldemarcated, primary nodular BCCs of the face, with a high rate $(20 \%)$ of incomplete excision [11]. When the excision is incomplete, another surgery is generally recommended. It is more complicated when the excision is complete but with a narrow margin. Only Mohs micrographic surgery can claim that excision is complete, owing to the analysis of all margins. In any case, it is essential to have a correct margin. To interpret the histological margin, it is useful to have data regarding retraction.

The surgeon correctly evaluated the localization of the smallest margin in only $55 \%$ of cases, demonstrating the difficulty for the clinician in evaluating the correct margin, because some tumours infiltrate lateral margins at a greater depth and some lesions are poorly limited. Some tools can help the surgeon or dermatologist to delimit margins of the tumour. In particular, the use of reflectance confocal microscopy was associated with a better rate of complete excision of melanoma and lentigo maligna compared with dermoscopically determined margins, as well as for basal cell carcinoma, although the data were more limited [12]. Dermoscopy and high-frequency ultrasound are also used to improve delimitation of margins [13].

The limitations of this study are the monocentric recruitment of patients and the heterogeneity of the diagnoses. Another limitation is the precision of the measurements in millimetres, for the margins in particular (especially for benign lesions for which margins are narrow). For the pathologist, a limitation is represented by the difficulty in macroscopically determining the limits of the tumour that can be modified by the disappearance of erythema after formalin fixation.

Also we could not study more accurately the difference in retraction according to the different areas of the face due to the insufficient number of cases. The study of the periorbital areas, which in practice seems to retract significantly after the excision, could be particularly interesting.

A complementary study could be useful with inking methods of the specimen margins and the lesion margins to determine more precisely these different measurements, and also to analyse retraction in more detail according to location, especially the face, which is a recurrent problem in current practice. Only one surgeon performed the excision, so the surgical method was reproducible. The surgeon in our study performed elliptical excision, so there was a narrow and a large margin. Elliptical excision is a standard method of skin tumour removal, but round excision with dog-ear repair can be considered as a good method, with better wound healing. Nevertheless, no study has compared these methods to compare the rate of incomplete removal $[14,15]$. 
Our study provides new data on the retraction of lesions and specimens, and especially of margins. These data are important to determine whether the excision of the lesion is complete, especially for BCC and SCC. Nevertheless, larger studies are needed to determine which differences could be tolerated before planning new interventions. 


\section{Acknowledgements}

We acknowledge the contributions of Aurélie Adriansen, Jocelyne Perrot and Laurence Moreau, pathologists who contributed to analyse the specimens, as well as Patrice Plantin for his encouragement and Sébastian Costa for correcting the English language.

\section{Take home messages / Key messages}

The retraction of the area of the specimen was significantly greater than the retraction of the lesion, which impacts the margins.

The localization and the duration of fixation were independent predictors of the specimen area retraction.

The surgeon correctly evaluated the localization of the smallest margin in just over half of the cases.

These data are useful for interpreting the sufficiency of margins on the histopathological report, especially for skin carcinomas. 


\section{References}

1. Dumas $\mathrm{P}$, Benatar $\mathrm{M}$, Cardot-Leccia $\mathrm{N}$, et al. Study of skin retraction applied to the treatment of skin tumors. Mapping of the human body. Ann Chir Plast Esthet 2012;57(2):118-24.

2. Kerns MJJ, Darst MA, Olsen TG et al. Shrinkage of cutaneous specimens: formalin or other factors involved? J Cutan Pathol 2008;35(12):1093-6.

3. Dauendorffer JN, Bastuji-Garin S, Guéro $S$ et al. Shrinkage of skin excision specimens: formalin fixation is not the culprit. Br J Dermatol 2009;160(4):810-4.

4. Blasco-Morente G, Garrido-Colmenero C, Pérez-López I, et al. Study of shrinkage of cutaneous surgical specimens. J Cutan Pathol 2015;42(4):253-7.

5. Blasdale C, Charlton FG, Weatherhead SC, et al. Effect of tissue shrinkage on histological tumourfree margin after excision of basal cell carcinoma. Br J Dermatol 2010;162(3):607-10.

6. Gregory N, Mulvaney M, Pattison T, et al. Shrinkage of skin excision specimens and downcoding. Arch Dermatol 2003;139(4):542-3.

7. Silverman MK, Golomb FM, Kopf AW, et al. Verification of a formula for determination of preexcision surgical margins from fixed-tissue melanoma specimens. J Am Acad Dermatol 1992;27(2 Pt 1):214-9.

8. Nahhas AF, Scarbrough CA, Trotter S. A Review of the Global Guidelines on Surgical Margins for Nonmelanoma Skin Cancers. The Journal of clinical and aesthetic dermatology 2017;10(4):37-46.

9. Ethun CG, Delman KA. The importance of surgical margins in melanoma. J Surg Oncol 2016;113(3):339-45.

10. Gualdi G, Monari P, Crotti S, et al. Matter of margins. J Eur Acad Dermatol Venereol 2015;29(2):255-61.

11. Kimyai-Asadi A, Alam M, Goldberg LH, et al. Efficacy of narrow-margin excision of welldemarcated primary facial basal cell carcinomas. J Am Acad Dermatol 2005;53(3):464-8.

12. Edwards SJ, Osei-Assibey G, Patalay R, et al. Diagnostic accuracy of reflectance confocal microscopy using VivaScope for detecting and monitoring skin lesions: a systematic review. Clin Exp Dermatol 2017;42(3):266-75.

13. Hayashi K, Uhara H, Okuyama R. Detection of the tumor margin of basal-cell carcinoma using dermoscopy and high-frequency ultrasound with narrow pieces of surgical tape as skin markers. Dermatol Surg 2014;40(6):704-6.

14. Hudson-Peacock MJ, Lawrence CM. Comparison of wound closure by means of dog ear repair and elliptical excision. J Am Acad Dermatol 1995;32(4):627-30.

15. Seo S-H, Son S-W, Kim I-H. Round excisions lead to shorter scars and better scar positioning than traditional elliptical excisions. Dermatology 2008;217(3):276-80. 


\section{Figures}

Figure 1: Schematic diagram with margins.

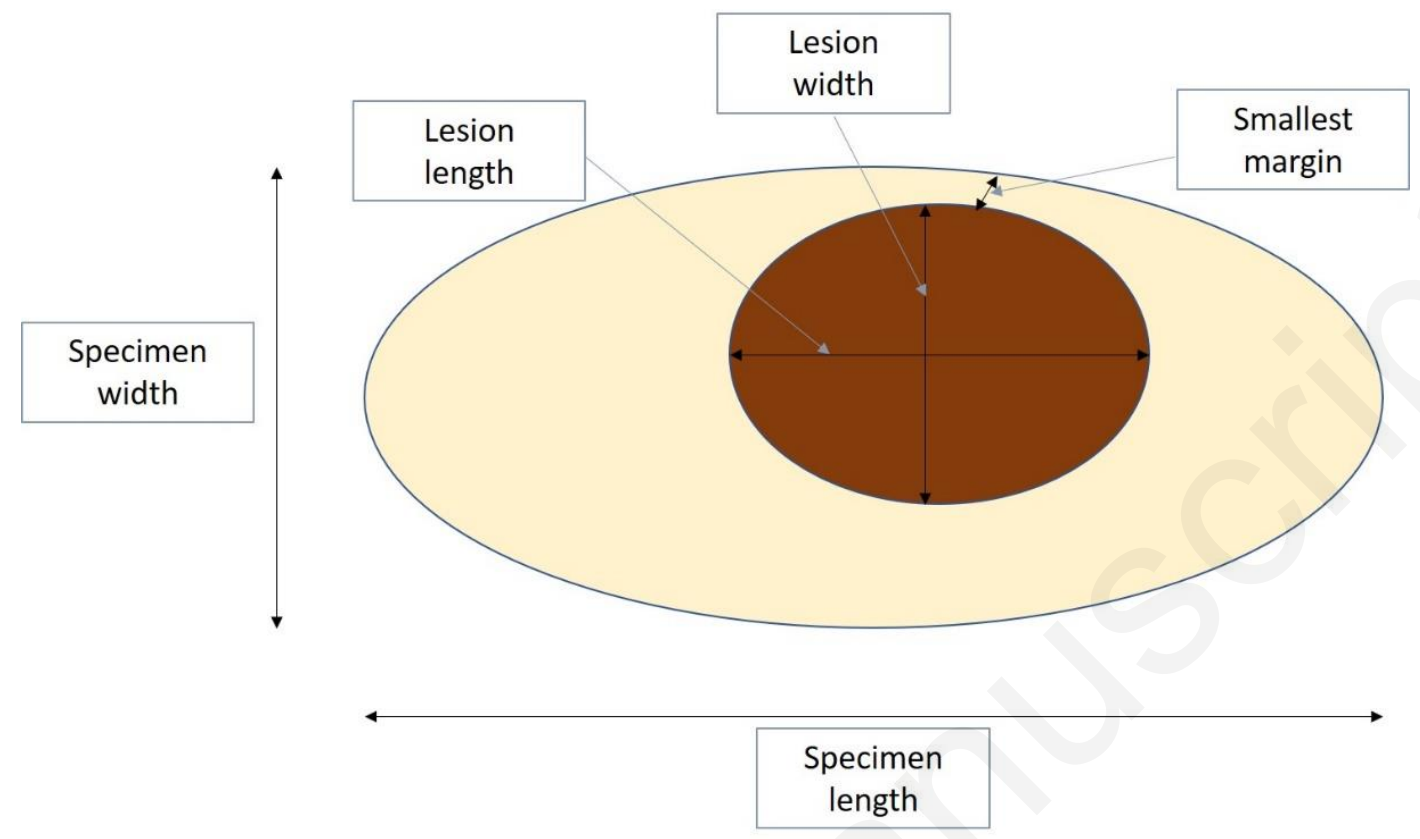

Figure 2: Percentage of retraction of specimen and lesion.

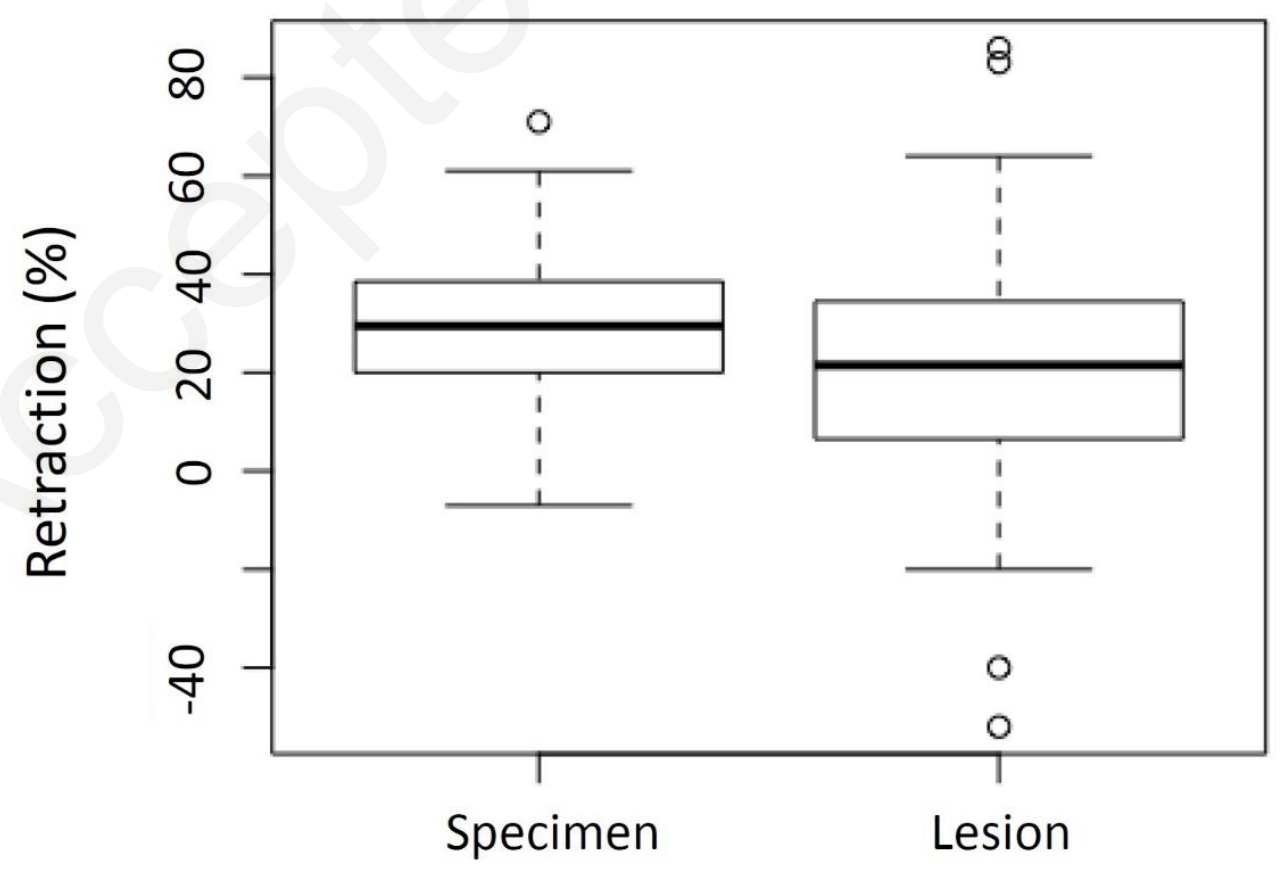

